\title{
K-Mean Cluster Analysis for Better Determining the Sweet Spot Intervals of the Unconventional Organic-Rich Shale: A Case Study
}

\author{
Muhammad Nur Ali Akbar ${ }^{1 *}$; Septian Tri Nugraha² \\ ${ }^{1}$ University of Miskolc, Petroleum Geoengineering, Miskolc Egyetemvaros, 3515, Hungary \\ ${ }^{2}$ China University of Petroleum-Beijing, 18 Fuxue Road, Changping, Beijing China 102249 \\ "Corresponding author: mn.aliakbar@gmail.com
}

Received: $1^{\text {st }}$ July, 2018

Accepted: $30^{\text {th }}$ July, 2018

\begin{abstract}
The petrophysical analysis is the crucial task for evaluating the quality of unconventional organic-rich shale and tight gas reservoirs. The presence of organic matter and the ultra-tight with over complex pore system have remained a lack of understanding of how to evaluate the extensive parameters of porosity considering organic content, gas saturation, organic richness, brittleness index, and sweet spot interval by only using conventional log. Therefore, this study offers effectively applied techniques and better analysis for interpreting these parameters by maximizing and integrating geological, geochemical, rock mechanical and engineering data.

In general, the field data used in this study are from the first dedicated well for source rock exploration in the North Sumatra Basin, Indonesia. The developed method was derived by using conventional log. All interpretation results were validated by laboratory data measurements of routine and special core analysis, petrography, total organic carbon (TOC) and organic maturation, and brittleness index (BI) calculation. Moreover, the high quality of NMR log data was used as well to ensure our developed techniques present good estimations. Briefly about the methods, we started to determine the total and effective porosity based on the density log by including the presence of organic matter and multi-mineral analysis in these estimations. Then, we used the revised water saturation-TOC of water saturation while the TOC was predicted in advance by averaging three results from the correlation of TOC-Density, modified CARBOLOG and Passey's $\Delta \operatorname{logR}$ methods. Equally important, in order to obtain the reliable gas saturation prediction, we used saturation exponent (n), cementation factor (m), and the tortuosity factor (a) parameters which obtained from laboratory measurement of formation resistivity factor and resistivity index (FFRI). In addition, the brittleness index was predicted based on sonic log data.

Finally, all parameters needed for determining gas shale sweet spot have been made. Then, we developed a way to evaluate the sweet spot interval by using K-mean clustering. In conclusion, this clustering result properly follows the shale quality index parameters which consist of organic richness and maturation, brittleness index, the storage capacity of porosity and gas saturation. This study shows that these petrophysical applied techniques leads us to interpret the best position of shale interval to be developed with a simple, fast, and accurate prediction way. Furthermore, as a novelty, this method can be used as rock typing method and obviously can reduce uncertainty and risks in organic-rich shale exploration.
\end{abstract}

Key words: Shale gas petrophysics, organic-rich shale, rock typing, cluster analysis, shale gas water saturation, sweet spot 


\section{Introduction}

The potency of organic-rich mudstones for shale gas resource in Indonesia was predicted around 574 trillion cubic feet (TCF) based on the data estimation from Geological Agency Ministry of Energy and Mineral Resources (GA-MEMR, 2011). This huge amount is distributed to several locations in Indonesia and unfortunately, the information about organicrich shale rocks characteristics are still too limited.

North Sumatra Basin (NSB) is one of Indonesia's basin that has potentially contained organic-rich in its shale formations such as Lower Baong Formation and Belumai Formation. One well was drilled in 2016 and it was dedicated for evaluating those formations properties. Through this well, all the needed data were obtained and we conducted various laboratory analysis and build an integrated study for evaluating the shale gas potency in the North Sumatra Basin.

Formation evaluation or petrophysical analysis is one of the most crucial tasks in characterizing the quality of the organic-rich shale formations. An extensive research is needed for evaluating this unconventional reservoir because of the complex pore system of shale brings us to conduct the integrated study such as combining and maximizing the data from the field (wireline log data) and laboratory data analysis from petrophysics, geochemistry, rock mechanics, and engineering.

Many rock grouping methods were developed in conventional reservoir rocks, but classifying the organic-rich shales are still rarely found especially by using wireline log data. Previous rock grouping techniques in organic-rich shale were dominantly presented based on core laboratory measurement such as Kale et al. (2010) in the Barnett shale gas plays and Gupta et al. (2012) in the Woodford shale which respectively introduced rock grouping method by using measurements of Total Organic Content (TOC), porosity, and concentration of clay and quartz. Moreover, Hammes et al. (2009) determined the lithofacies based on an extensive core database in the Haynesville shale-gas formation.

The previous study about rock grouping based on well-logs data was from Popielski et al. (2012). He demonstrated the rock typing method based on estimates of total porosity, kerogen, and minerals concentration volume, and fluid saturation from nonlinear joint inversion in the Barnett and the Haynesville shale-gas plays. While Aranibar et al. (2013) considered the similar parameters and added elastic rock properties on its rock classification due to its importance in determining the quality of the organic-rich shale in the Haynesville shale-gas formation. However, these methods were conducted based on complex solving method and equations. Therefore, this paper presents an integrated workflow to characterize and evaluate the organic-rich shale reservoir based on petrophysical analysis and also develops a simple, fast and accurate method to determine sweet spot (the best target zone) intervals by using $\mathrm{K}$-mean clustering and it applied to the case study of organic-rich shales in the North Sumatra Basin.

\section{Applied methods}

In order to determine sweet spot interval by only using conventional log, there are several steps to be done in order to assign them as much as determination of clay volume, total organic carbon (TOC), porosity, water saturation, permeability, and brittleness index (BI).

\section{Clay volume}

Firstly, the clay volume in this study has been interpreted from spectral gamma ray log. This becomes important owing to the TOC is uranium rich, predicting clay volumes exclusively overestimated if it was interpreted by using standard total gamma ray. Then, the results of clay volume interpretation are 
validated by clay volume that measured from XRay Diffraction (XRD) analysis.

\section{Total Organic Carbon (TOC)}

Next, the TOC is priory predicted for making an accurate calculation of porosity in organic-rich shale. This parameter is identified by implementing the $\triangle \log R$ (Passey et al. 1990) and Modified CARBOLOG (Liu, 2008). This following equation is the algebraic expression that was used by Passey is:

$$
\begin{aligned}
& \Delta \log R=\log _{10}\left(\frac{R}{R_{\text {baseline }}}\right)+ \\
& +0.02 \times\left(\Delta t-\Delta t_{\text {baseline }}\right)
\end{aligned}
$$

Baseline is determined when sonic $(\Delta t)$ and resistivity $(R)$ directly overlaid each other or they just tracked each other. TOC can then be calculated from the following equation by knowing level of maturity (LOM).

$$
T O C=\Delta \log R \times 10^{(2.297-0.1688 \times L O M)}
$$

This following relationship is a Modified CARBOLOG technique that derived by Liu $e t$ al. (2008) owing to the prior method of the CARBOLOG (Carpentier et al., 1991) needs to know at least three client-side materials and the chart is easy to understand but difficult to calculate TOC (Akbar and Musu, 2017).

$T O C=a \Delta t+b R^{-1 / 2}+c$

where $a, b$, and $c$ are constant coefficients which gained from non-linear regression of multivariable.

The last applied method is the linear regression between the bulk density log and the weight percent of TOC. Correlation of core and cutting TOC values to density log data leads to useful relationships for specific reservoirs. Schmoker and Hester, (1983) proposed the correlation between weight percent of TOC and density $\log$ in their case study in the very organic rich Upper and Lower Bakken Shales,
North Dakota and Montana. This method was used as well in the case study of Sichuan Basin, China, by Huang, (2015).

The final TOC are assigned from averaging of these three TOC calculations in order to decrease the uncertainties of estimation (Akbar et al., 2018). Eventually, the weight percent of TOC measurement from geochemical laboratory is used in validating the TOC estimation from log interpretation.

\section{Shale Porosity}

Porosity is one of the key parameters for "sweet spot" determination refer to its hydrocarbon storage capacity. In conventional reservoir cases, the density log is commonly used in interpreting the total porosity. However, due to the complexity of unconventional shale characteristic such as the presence of organic matter with its low-density organic material and some hydrocarbon exists as a condensed absorbed phase, therefore, the porosity equation is modified by including the TOC component (Sondergeld et al., 2010) as follows:

$\emptyset_{T}=\frac{\left(\rho_{m a}-\rho_{b}\right)+\rho_{b}\left(W_{T O C}-\rho_{m a} \frac{W_{T O C}}{\rho_{T O C}}\right)}{\rho_{m a}-\rho_{f}}$

where $\emptyset_{T}$ is the total density porosity, $\rho_{m a}$ is the solid matrix density, $\rho_{b}$ is the bulk density, $W_{T O C}$ is TOC weight fraction, $\rho_{T O C}$ is organic material or kerogen density, and $\rho_{f}$ is the fluid density.

\section{Water Saturation}

Prediction of water saturation for organic-rich shale is strongly influenced by the presence of organic content. As the prior description model of storage capacity in the gas shale for absorbed gas, this phenomenon will affect the amount of gas saturation in the shale formation. Some studies suggest that $50 \%$ of the total gas storage in the Devonian shale exists as a condensed adsorbed phase (Lu et al., 1995). Therefore, the Equation 5 was developed by considering pore 
space characteristics, organic matter characteristics, mineralogical composition, and geological conditions.

Refer to the previous publications by $\mathrm{Xu}$ et al., 2017 and Zhang et al., 2016, their developed method of the revised water-saturation-TOC presented a very good result on water saturation prediction in the Longmaxi-Wufeng shale, south eastern Sichuan Basin, China. The applied equation of the revised watersaturation-TOC is formulated as follows:

$S_{w}=a \times S_{w c o n} \times\left(b-\frac{T O C}{T O C_{\max }}\right)$

where $a$ and $b$ are coefficients ( $a=1$ and $b=$ 1 ); $T O C_{\max }$ is the maximum TOC, $\%$; and $S_{w c o n}$ is the conventional Archie water saturation model.

\section{Brittleness Index}

Brittleness index is one of valuable parameters in organic-rich shale formation evaluation due to its potential to make successfully in hydraulic fracturing treatments. The value of brittleness is a complex function of lithology, mineral composition, TOC, effective stress, reservoir temperature, diagenesis, thermal maturity, porosity, and type of fluid (Wang and Gale, 2009). In another approach, a brittleness index is defined as combining of Poisson's ratio, $v$, and Young's modulus, E (Rickman et al., 2008; Grieser and Bray, 2007). These two components are combined to reflect the rock strength to fail under stress (Poisson's ratio) and to maintain a fracture (Young's modulus) once the rock fractures (Rickman et al., 2008). By using following formulas, these parameters can be calculated as functions of compressional and shear velocities:

$$
\begin{aligned}
& E=\frac{\rho V_{s}^{2}\left(3 V_{p}^{2}-4 V_{s}^{2}\right)}{V_{p}^{2}-V_{s}^{2}} \\
& v=\frac{V_{p}^{2}-2 V_{s}^{2}}{2\left(V_{p}^{2}-V_{s}^{2}\right)}
\end{aligned}
$$

where $\rho$ is bulk density and $V_{p}$ and $V_{s}$ are compressional and shear wave velocities, respectively. Then, $E$ and $v$ are normalized using following formulas:

$E_{\text {brittle }}=\frac{E-E_{\min }}{E_{\max }-E_{\min }}$
$v_{\text {brittle }}=\frac{v-v_{\min }}{v_{\max }-v_{\min }}$

and then, the brittleness index (BI) is defined as follows:

$B I_{\text {sonic }}=\frac{E_{\text {brittle }}+v_{\text {brittle }}}{2} \times 100 \%$

Many researchers (Jarvie et al., 2007; Wang and Gale, 2009; and LEMIGAS, 2013) have defined the brittleness upon the basis of mineralogical composition. The used data are usually from $X$ ray powder diffraction (XRD) and or energydispersive X-ray spectroscopy setting on the scanning electron microscopy (EDX-SEM). In this paper, the calculation of brittleness index is conducted through Wang and Gale's, $B I_{W}$ equation and the result is compared to the BI estimation from sonic log. This equation is presented as follows:

$B I_{w}=\frac{Q_{z}+D o l}{Q z+C a l+T O C+C l y+D o l}$

where $Q z$ is the fractional quartz content, $\mathrm{Fel}$ is the feldspar, $\mathrm{Dol}$ is the dolomite content, $\mathrm{Cal}$ is the calcite content, TOC is the total organic carbon content, and Cly is the clay content by weight in the rock.

\section{Cluster Analysis}

In this process, the objects are grouped based on key properties for determining shale gas formation sweet spot. This clustering method uses the K-mean statistical technique to cluster the data into a known entered number of clusters. For this to work an initial guess has to be made of the mean value of each cluster for each input log. The initial guess can affect the 
results and in order to get good results the initial values should cover the total range of the logs.

$\mathrm{K}$-mean clustering works by assigning each input data point to a cluster. The routine tries to minimize the within-cluster sums of squares of the difference between the data point and the cluster mean value. The routine works by calculating the sum of the squares difference for a data point and each cluster mean and assigning the point to the cluster with the minimum difference. Once all the data points have been assigned to the clusters the new mean values in each cluster are calculated. Using the new mean values the routines starts again re-assigning the data to the clusters. This loop continues until the mean values do not change between loops. These then become the results.

All input log data is normalized (standardized) before starting so that each input $\log$ has the same dynamic range. The normalization is done by calculating the mean and standard deviation of the $\log$ and then normalizing the data by subtracting the mean and dividing by the standard deviation. Hence a normalized log data value of 1.0 or -1.0 will be one standard deviation.

After all of the petrophysical properties have been already determined, cluster definition can be defined based on parameters of water saturation, total organic content, and brittleness index. In this case study, we defined six clusters from these three parameters and we applied directly to the established clustering program for creating the ideal clusters from the input parameters.

\section{Data sources}

The data used of organic-rich shale were compiled by Akbar and Musu (2017) for well $\log$ and laboratory measurements data.

\section{Well Log Data}

In general, all of data were collected from a dedicated well for organic-rich shale exploration in the North Sumatra Basin (NSB).
The expected formations for this shale were Baong and Belumai formations. The main used data were conventional logging data consisted of Gamma-Ray, Resistivity Log, Neutron Log, Density Log, Sonic Log, and PEF. Moreover, the high quality of NMR log data was used as well to validate our effective porosity result by using density log.

\section{Laboratory Data}

There are 50 core plug samples that taken from three sections of whole core and 12 samples were taken from sidewall core (SWC) with good conditions. These samples are used for conducting a routine core analysis (RCA) in order to obtain at least the data of porosity, permeability, and grain density. Furthermore, 15 core samples are conducted as well for identifying the pore size distribution by applying mercury injection capillary pressure (MICP). In order to obtain the reliable gas saturation prediction, determining saturation exponent $(n)$, cementation factor $(m)$, and the tortuosity factor $(a)$ parameters are based on laboratory measurement of formation resistivity factor and resistivity index (FFRI).

In general, the range and average porosity, air permeability, and grain density are shown in the Table.1. The relationship between porosity and permeability from RCA (Fig.1) in the Lower Baong Formation (Core 1 \& Core 2) gives a relatively good correlation, while in Belumai Formation (Core 3) shows the different trend due to the present of active microfractures. In addition, pore size distribution resulted from MICP test was dominated by size of 0.01 to $0.1 \mu \mathrm{m}$ while pore size below $0.01 \mu \mathrm{m}$ was not invaded by mercury and considered as wetting phase (air) saturation.

\section{Petrography analysis}

Through the analysis of thin section, XRD and SEM-EDX, the Lower Baong Formation is represented by 32 samples which consist of 22 SWC and 10 core plugs. All samples were determined as claystone. While seven selected 
Tab.1. Summary of routine core analysis for porosity, permeability, and grain density measurements.

\begin{tabular}{|c|c|c|c|c|c|}
\hline \multirow{2}{*}{$\begin{array}{c}\text { Core Sample } \\
\text { Type }\end{array}$} & \multirow{2}{*}{ Core Interval } & \multirow{2}{*}{ Parameters } & \multicolumn{2}{|c|}{ Range } & \multirow{2}{*}{ Average } \\
\hline & & & Min & Max & \\
\hline \multirow{9}{*}{ Conventional } & \multirow{3}{*}{$\begin{array}{c}\# 1 \\
(2016-2034 \mathrm{~m})\end{array}$} & Porosity $(\%)$ & 0.22 & 4.59 & 2.14 \\
\hline & & Air Permeability (md) & 0.000277 & 0.033348 & 0.001955 \\
\hline & & Grain density (gr/cc) & 2.37 & 2.55 & 2.49 \\
\hline & \multirow{3}{*}{$\begin{array}{c}\# 2 \\
(2482-2501 \mathrm{~m})\end{array}$} & Porosity $(\%)$ & 0.07 & 2.46 & 1.18 \\
\hline & & Air Permeability (md) & 0.000328 & 0.222602 & 0.001347 \\
\hline & & Grain density (gr/cc) & 2.42 & 2.53 & 2.47 \\
\hline & \multirow{3}{*}{$\begin{array}{c}\# 3 \\
(3273-3282 \mathrm{~m})\end{array}$} & Porosity $(\%)$ & 0.22 & 0.39 & 0.34 \\
\hline & & Air Permeability (md) & 0.000674 & 0.873587 & 0.006566 \\
\hline & & Grain density (gr/cc) & 2.59 & 2.64 & 2.61 \\
\hline \multirow{3}{*}{ Sidewall core } & \multirow{3}{*}{$(1719-3263 \mathrm{~m})$} & Porosity $(\%)$ & 0.1085 & 2.626 & 0.7902 \\
\hline & & Air Permeability (md) & 0.000202 & 0.171782 & 0.002562 \\
\hline & & Grain density (gr/cc) & 2.401 & 2.581 & 2.457 \\
\hline
\end{tabular}

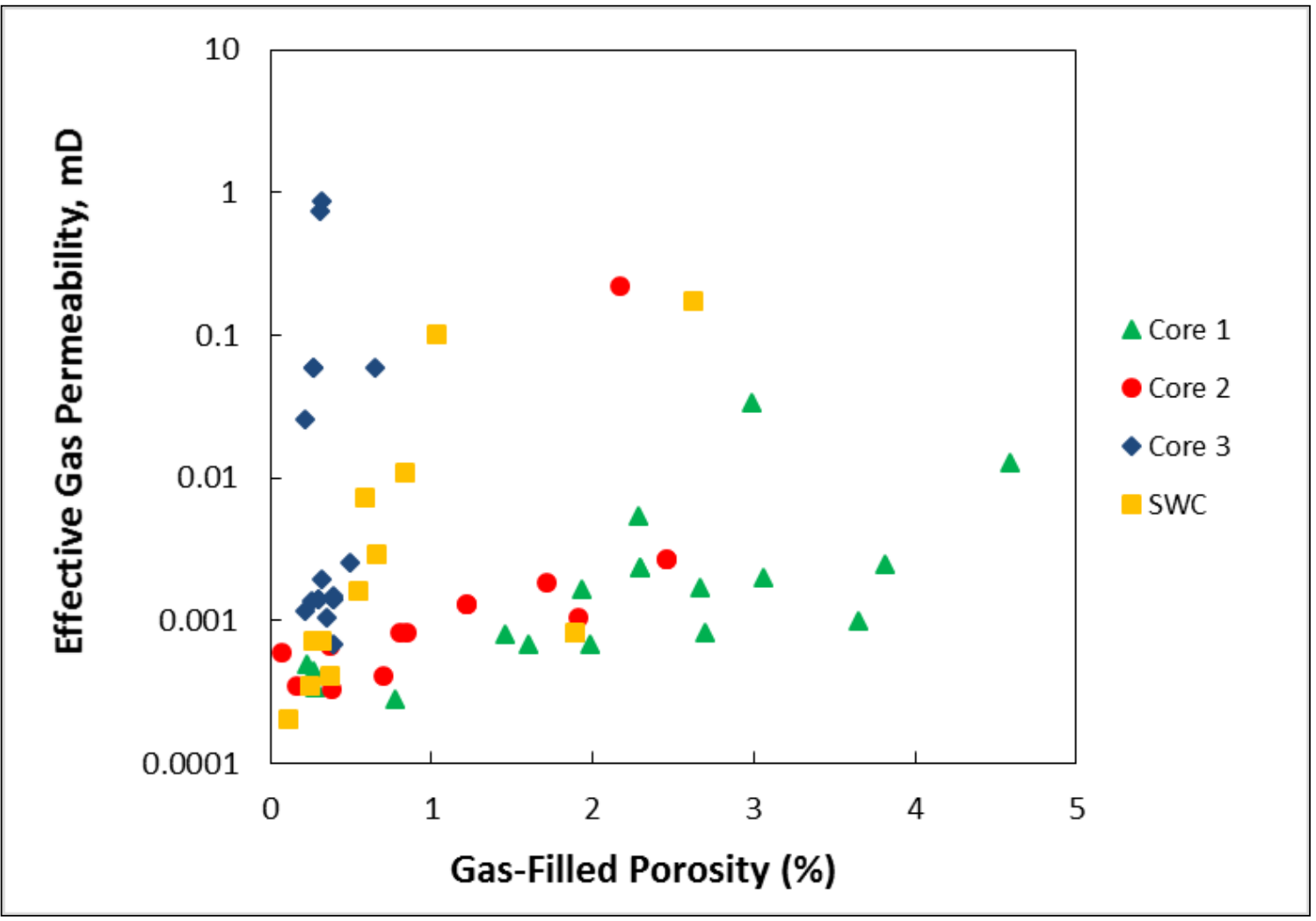

Fig.1. Porosity vs permeability cross plot

samples are analyzed from Belumai Formation including 2 SWC and 5 core plug samples. Based on petrographic examination, 3 samples are identified as fossiliferous siltstone, 2 samples are identified as sandy limestone facies and 2 samples are identified as fossiliferous sandstone.

Figure 2 presents ternary diagrams that illustrates the distributions of mineralogy contained in the organic-rich shale of Lower 
Baong Formation and Belumai Formation. These of diagrams also could be used as a parameter to evaluate the brittleness index as a function of mineralogy. In general, by reviewing the mineral distributions of Lower Baong and Belumai Formation. In general, based on the brittleness index calculation (Eq. 11) on 39 samples of XRD analysis results, lithology in lower Baong Formation has poor to good degree of brittleness and while in Belumai Formation has dominantly good brittleness index. The brittleness index increases with deeper depth, as well as the proportion of quartz minerals and carbonates.

\section{Geochemical Analysis}

Geochemical analysis measured the organic richness and maturation for both core and cutting samples in term of source rock potential evaluation. As one of a crucial parameter, the weight percent of TOC has been investigated by using rock-eval pyrolysis. The result of TOC measurement is presented in Figure 3. In general, the amounts of the presence TOC from our samples are relatively below than $2 \%$. It means that the quality of gas shale potential shows the range of fair to good while several samples from Belumai Formation point to the poor quality. Another investigation which based on hydrocarbons generated by thermal cracking or residual hydrocarbon potential (S2) shows dominantly in the poor quality of shale becoming a source rock for both formations. However, the calculated TOC in this laboratory results did not totally give valid amounts, because the hesitancy while the samples were cleaned from oil-based mud (OBM) contaminated by using organic solvent. In this case, the OBM and free hydrocarbon contained in the sediment have similar solubility to organic solvent. Therefore, some of the weight carbon (mainly free hydrocarbon) in the rock samples were cleaned too. Besides that, the amount of decreased free hydrocarbon was difficult to be predicted statistically due to the OBM contaminant in each sample was not uniform. The retention time of cleaning also determined the amount of dissolved OBM and free hydrocarbon by organic solvent. Consequently, the amounts of TOC possibly give the lower value than the real reservoir condition (more pessimist) (Akbar et al., 2018).

Furthermore, this TOC result was still used to validate the TOC prediction by using well log interpretation through its pessimist result. In addition of information from this laboratory investigation provided us to identify the type of kerogen based on modified van Krevelen diagram by using hydrogen-to-carbon and the oxygen-to-carbon ratio (Tissot and Welte, 1984). Through this interpretation, both Lower Baong Formation and Belumai Formation are dominated by the type III kerogen and mixed of type II and type III kerogen. These kerogen types are potentially expected to generate the gas and/or high shrinkage oil hydrocarbons. Besides that, kerogen type has an influence on the gas storage capacity as it is gas sorption capacities where it decreases in the following order: type III > type II > type I (Zhang et al., 2012).

\section{Result and Discussion}

The study for determining sweet spot area has been conducted. Applied methods that have been explained above are used to amplify petrophysical analysis results. All calculations needed to support K-Mean clustering method are well-presented in this section.

\section{Total organic carbon (TOC)}

The determination of TOC is very important in case of organic-rich shale. Because it can affect other properties such as porosity, water saturation, and especially for clustering in order to get better sweet spot determination. Based on Figure 4, TOC determinations are applied in this study. These results, presented in column 10 (Figure 4, Appendix), are compared to laboratory data (black points). The estimated average TOC shows good match with 
laboratory data. This final result subsequently can be used to predict other properties in this study.

\section{Porosity}

Getting better prediction of porosity is important due to its function as storage capacity parameter in organic-rich shale. In this study we predict porosity by considering TOC that has been calculated above. Porosity obtained from RCA is an effective porosity that only measure the interconnected pores. This data thereafter is used in validating the effective porosity in the $\log$ interval. From Figure 4 (shown in Appendix), column 9, it can be seen that the prediction of PHIE gives very good estimated result. And we can see that the value of total porosity is TOC dependent. The higher amount of kerogen content in the shale layer would give the higher the estimated total porosity.

\section{Brittleness Index}

In order to get better clustering analysis, brittleness index should be calculated correctly. As mentioned before, two methods are used to evaluate the brittleness by using sonic log and mineralogy calculation. BI from sonic log was estimated by implementing long step calculations from Equation 6 to 10. Then the BI calculation based on mineralogy was conducted by using Eq. 11. From figure 4 (shown in Appendix), column 12, it can be seen that the calculation of BI by considering mineralogical composition indicate the higher value and some of them indicate otherwise. This could explain that brittleness index is a complex function of different parameters not only mineralogical composition. Therefore, it seems that BI generated from sonic could present a better estimation in order to support clustering analysis.

\section{Clustering Analysis}

As mention before that sweet spots in shale reservoirs may be defined by source rock richness or thickness, by natural fractures, or by other factors, using geological data such as core analysis, well log data, or seismic data. In order to acquire sweet spot intervals, the clustering analysis has been conducted. From Table 2, it can be seen that rock clustering definitions are based on parameters Sw, BI and TOC. The best cluster is the cluster number one (1) which explains as the sweet spot cluster. Figure 5 (shown in Appendix) shows cluster plot per each cluster based on rock clustering definition. Eventually, all interpreted petrophysical analysis are conducted for Lower Baong Formation to Belumai formation in Figure 4 (shown in Appendix). Regarding to objective of this paper, it could be sum up that sweet spot interval based on K-Mean Clustering is potentially in the interval of $1704-1772 \mathrm{~m}$; 1840 - 1930m; and 2901 - 3039m of Lower Baong formation while in the Belumai Formation the sweet spot intervals appears in very thin layers. Although the shale in Belumai Formation is very brittle, but the TOC is relatively low and the water saturation is very high.

Tab.2. Rock Clustering Definitions

\begin{tabular}{cc}
\hline Cluster & Definitions \\
\hline 1 & $\mathrm{Sw}<58 \% ; \mathrm{BI}>48 \%$ and $\mathrm{TOC}>1.2 \%$ \\
2 & $\mathrm{Sw}<58 \% ; \mathrm{BI}<48 \%$ and $\mathrm{TOC}>1.2 \%$ \\
3 & $\mathrm{Sw}>58 \% ; \mathrm{BI}<48 \%$ and $\mathrm{TOC}>1.2 \%$ \\
4 & $\mathrm{Sw} \approx 58 \% ; \mathrm{BI} \approx 48 \%$ and $\mathrm{TOC} \approx 1.2 \%$ \\
5 & $\mathrm{Sw}>58 \% ; \mathrm{BI}<48 \%$ and $\mathrm{TOC}<1.2 \%$ \\
6 & $\mathrm{Sw}>58 \% ; \mathrm{BI}>48 \%$ and $\mathrm{TOC}<1.2 \%$ \\
\hline
\end{tabular}




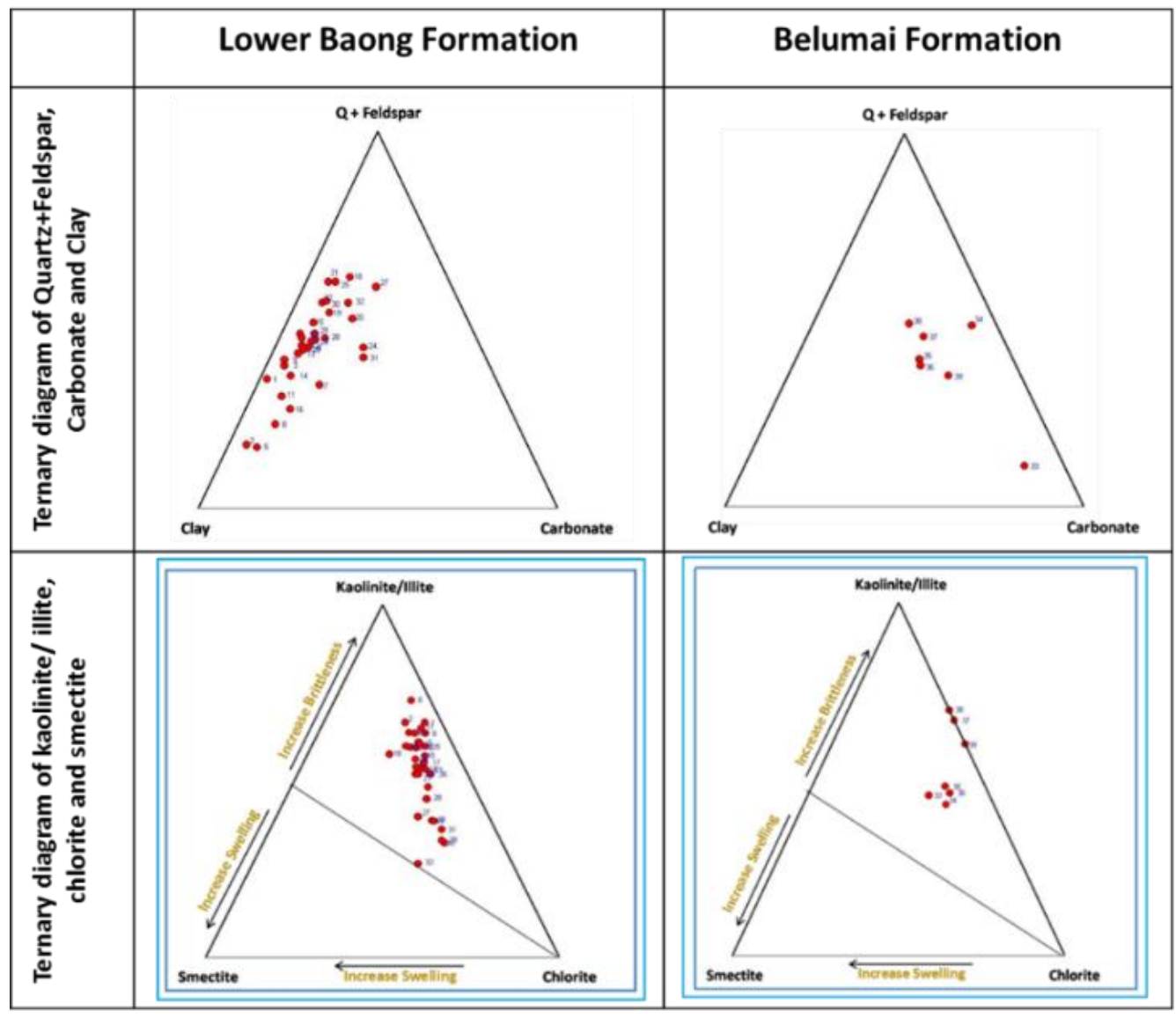

Fig.2. Ternary diagram of shale mineralogy from XRD analysis

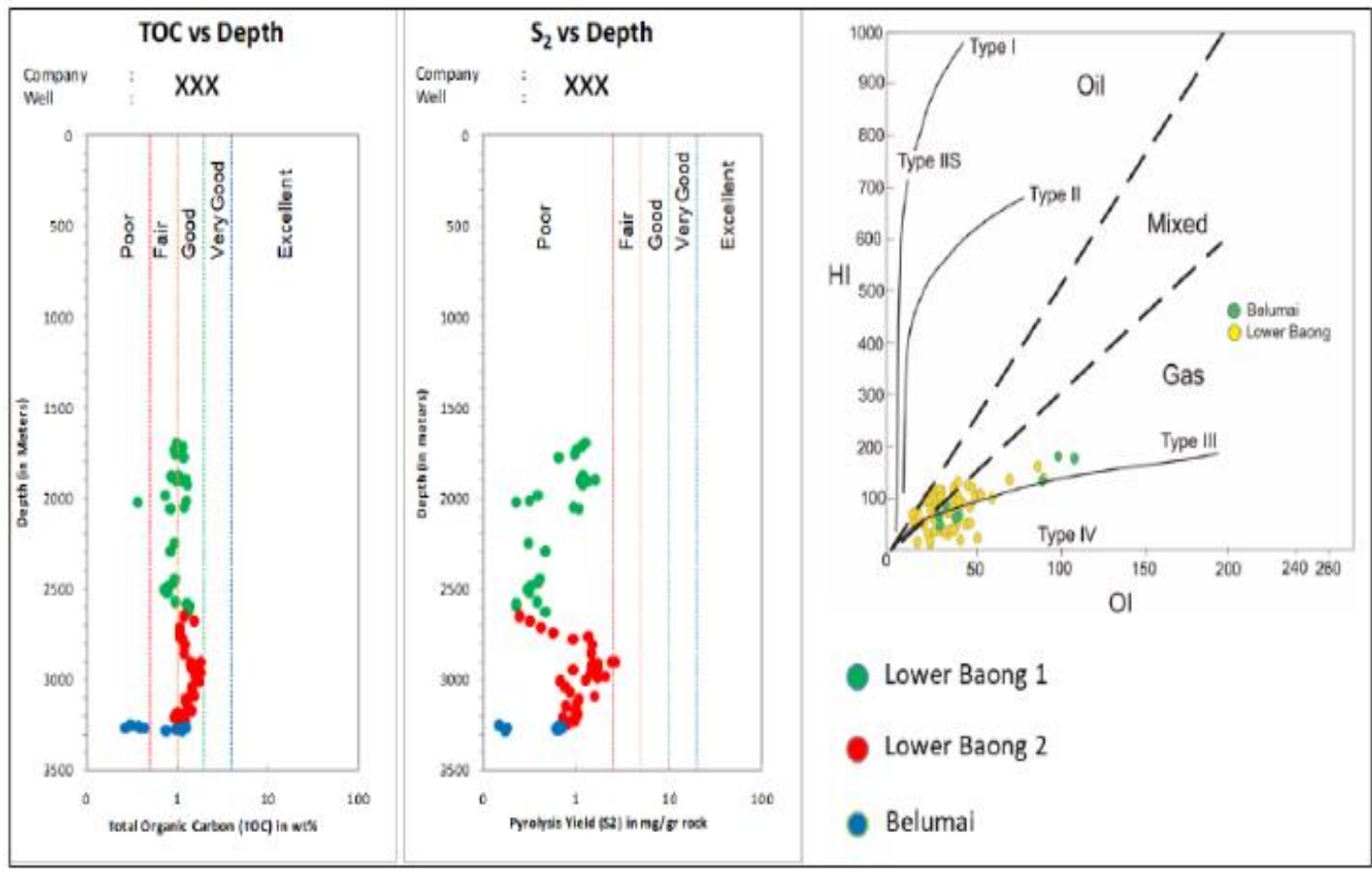

Figure 3. Source rock potential and its quality distribution in the depth interval based on TOC and $\mathrm{S}_{2}$ 
In addition, Figure 6 (shown in Appendix) presents the representative SEM photographs and descriptions of these sweet spot intervals.

\section{Conclusion}

The following are conclusions drawn from the present study.

1. The petrophysical interpretation results for evaluating organic-rich shale in the North Sumatra Basin are conducted by integrating and maximizing data analyses of petrophysical, geological, geochemical, and rock mechanical.

2. The potential zones are in the Lower Baong Formation, in the depth intervals of 1704 - 1772m; 1840 - 1930m; and 2901 $3039 \mathrm{~m}$

3. K-mean Clustering allowed us defined a number of clusters that we desire, and based on that set number, gather the information depending on the distance between the data and the centroids.

4. This offered methodology can be used for further petrophysical evaluation either in the case of shale gas exploration or shale gas development fields.

5. In the analyzed case, clustering is a useful method that allowed us to define the sweet spot, which is defined when brittleness, water saturation and TOC criteria are met.

\section{References}

Akbar A, Nur M., Musu JT. (2017) Rock typing and shale quality index methods based on conventional log a case study for organicrich shale in the North Sumatra Basin. In: 23rd Formation Evaluation Symposium of Japan, Society of Petrophysicists and WellLog Analysts, Japan, 11-12 October (JFES2017-T)

Akbar A, Nur M., Musu JT., and Milad B. (2018) Water Saturation Interpretation Model for Organic-Rich Shale Reservoir: A Case Study of North Sumatra Basin. The
Unconventional Resources Technology Conference held in Houston, Texas, USA, 23-25 July. URTeC: 2879229, DOI: 10.15530/urtec-201 8-2879229.

Aranibar A., Saneifar, M., and Heidari, Z. (2013) Petrophysical rock typing in organic-rich source rocks using well logs. the Unconventional Resources Technology Conference held in Denver, Colorado, USA, 12-14 August 2013. SPE 168913 / URTeC 1619574.

Carpentier B, Huc A.Y, Bessereau G. (1991) Wireline logging and source rocks Estimations of organic carbon content by CARBOLOG method. Log Analysts, 1991, 32(3):279-297.

Geological Agency (2011) Map of Distribution and Potential of Shale Oil and Gas Bearing Formation of Indonesia. Quaternary. Neogene. Paleogene.

Grieser WV, Bray JM. (2007) Identification of production potential in unconventional reservoirs. Production and Operations. SPE Symposium of Oklahoma City, OK, USA, March 31-April 3. SPE 106623.

Gupta, N., Rai, C. S., and Sondergeld, C. H. (2012) Integrated Petrophysical Characterization of the Woodford Shale in Oklahoma. The SPWLA 53rd Annual Logging Symposium, Cartagena, Colombia, 16-20 June.

Hammes, U., Eastwood, R., Rowe, H. D., and Reed, R. M. (2009) Addressing Conventional Parameters in Unconventional Shale-Gas Systems: Depositional Environment, Petrography, Geochemistry, and Petrophysics of the Haynesville Shale. The 29th Annual GCSSEPM Foundation Bob F. Perkins Research Conference, Houston, USA, 6-8 December.

Jarvie DM, Hill RJ, Ruble TE, Pollastro RM. (2007) Unconventional shale-gas systems: The Mississippian Barnett Shale of northcentral Texas as one model for thermogenic 
shale-gas assessment. AAPG Bull 2007; 91:475-499.

Kale, S., Rai, C. S., and Sondergeld, C. H. (2010) Rock Typing in Gas Shales. The SPE ATCE, Florence, Italy, 19-22 September. SPE 134539.

LEMIGAS (Research and Development Center for Oil and Gas Technology), Ministry of Energy and Mineral Resources (ESDM). (2013) Pilot Project - Search and Discovery of Shale Gas Reserves: unpublished report.

Passey QR, Creaney S, Kulla JB, Moretti FJ, Stroud JD. (1990) A practical model for organic richness from porosity and resistivity logs: AAPG Bull 74:1777-1794.

Popielski, A. C., Heidari, Z., and TorresVerdin, C. (2012) Rock Classification from Conventional Well Logs in HydrocarbonBearing Shale. The SPE ATCE, San Antonio, Texas, USA, 8-10 October. SPE 159255.

Rickman R, Mullen MJ, Petre JE, Grieser WV, Kundert D. A. (2008) Practical use of shale petrophysics for stimulation design optimization: All shale plays are not clones of the Barnett Shale. SPE Annual Technical Conference and Exhibition, Denver, CO, USA, September 21-24. SPE 115258.

Sondergeld CH., Newsham KE., Comisky JT., Rice MC., Rai CS. (2010) Petrophysical considerations in evaluating and producing gas shale resources. SPE Unconventional Gas Conference; Pittsburgh, PA, USA. February 23-25. SPE131768.

Tissot, B. P., and Welte, D. H. (1984) Petroleum Formation and Occurrence. SpringerVerlag; New York, 699 pp.

Wang, F.P. and Gale, J. (2009) Screening criteria for shale-gas systems. Gulf Coast Association of Geological Societies 59th Annual Convention, 27-29 September, Shreveport, LA.

Xu J., Lei X., and Yuxing Q. (2017) Two effective methods for calculating water saturations in shale-gas reservoirs. Geophysics, vol. 82, no. 3 (may-june 2017); p. D187-d197.

Zhang, Baoying, and Jingling $\mathrm{Xu}$ (2016) Methods for the evaluation of water saturation considering TOC in shale reservoirs. Journal of Natural Gas Science and Engineering pp. 800e810, Elsevier, http://dx.doi.org/10.1016/j.jngse.2016.11.0 23.

Zhang T, Ellis GS, Ruppel SC, Milliken K, Yang R. (2012) Effect of organic- matter type and thermal maturity on methane adsorption in shale- gas systems. Org Geochem 2012;47:120-131. 


\section{Appendices}

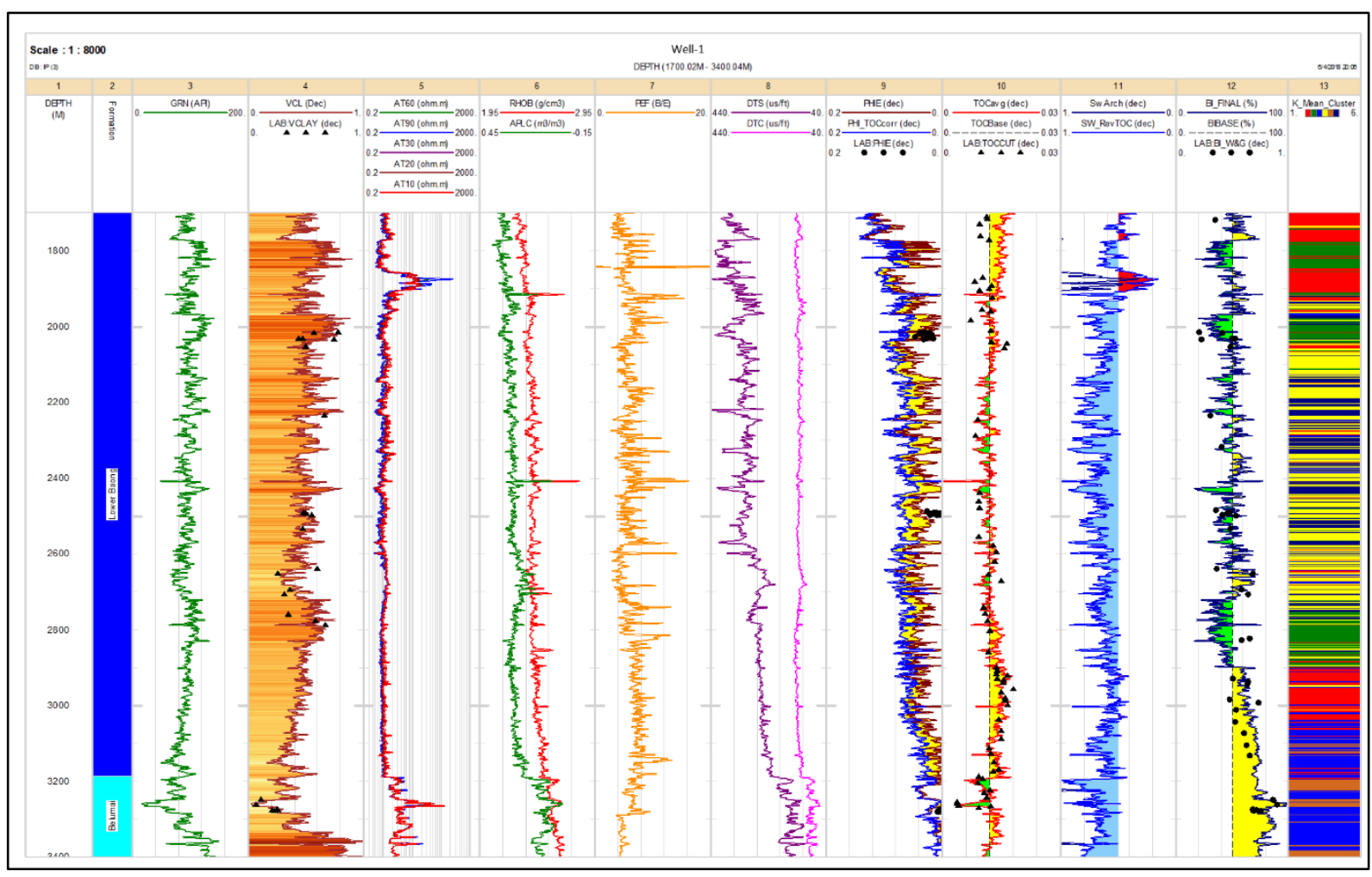

Figure 4. All results of organic-rich shale petrophysical analysis based on conventional log 


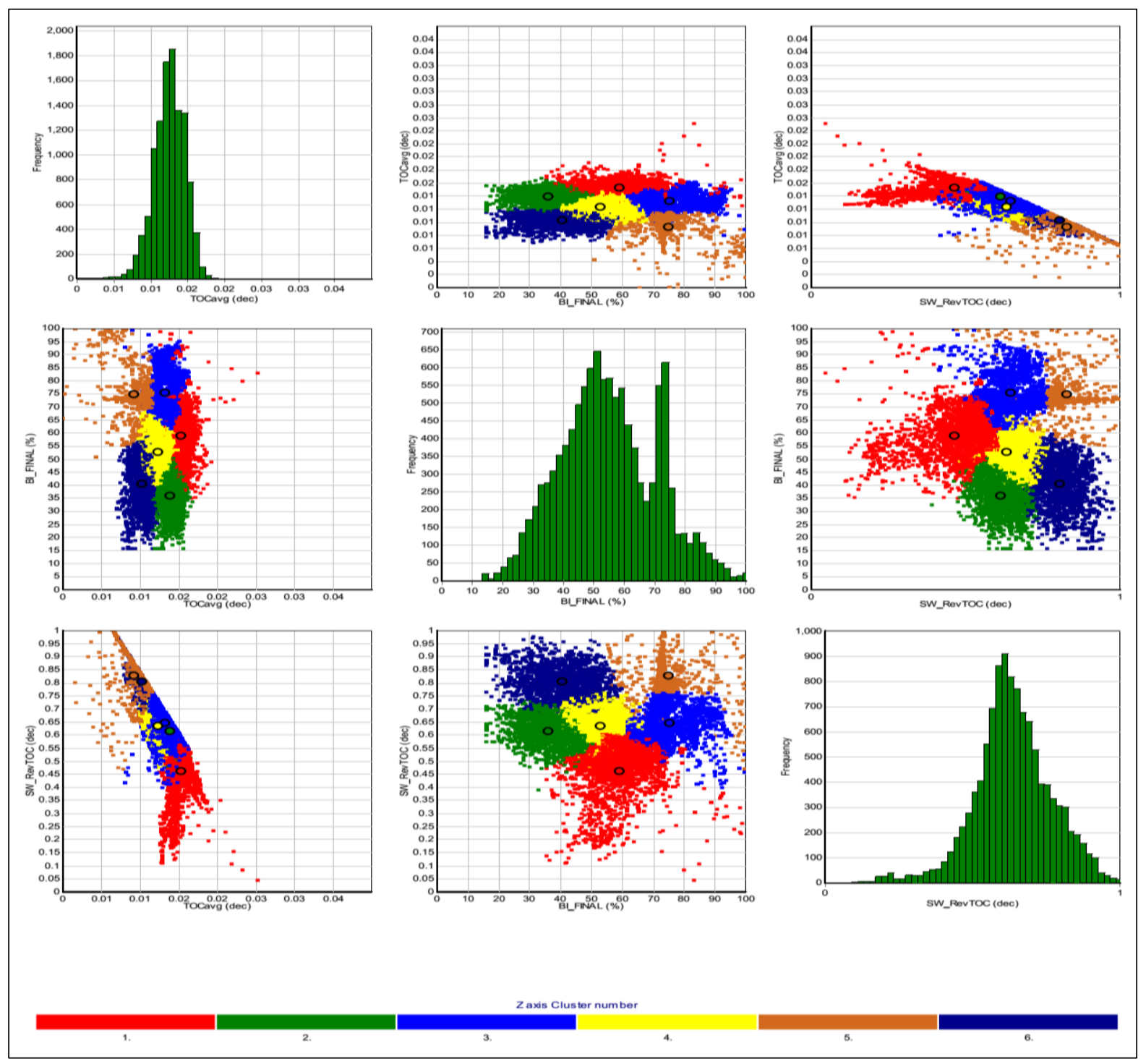

Figure 5. Multi-curve Cluster Crossplot 

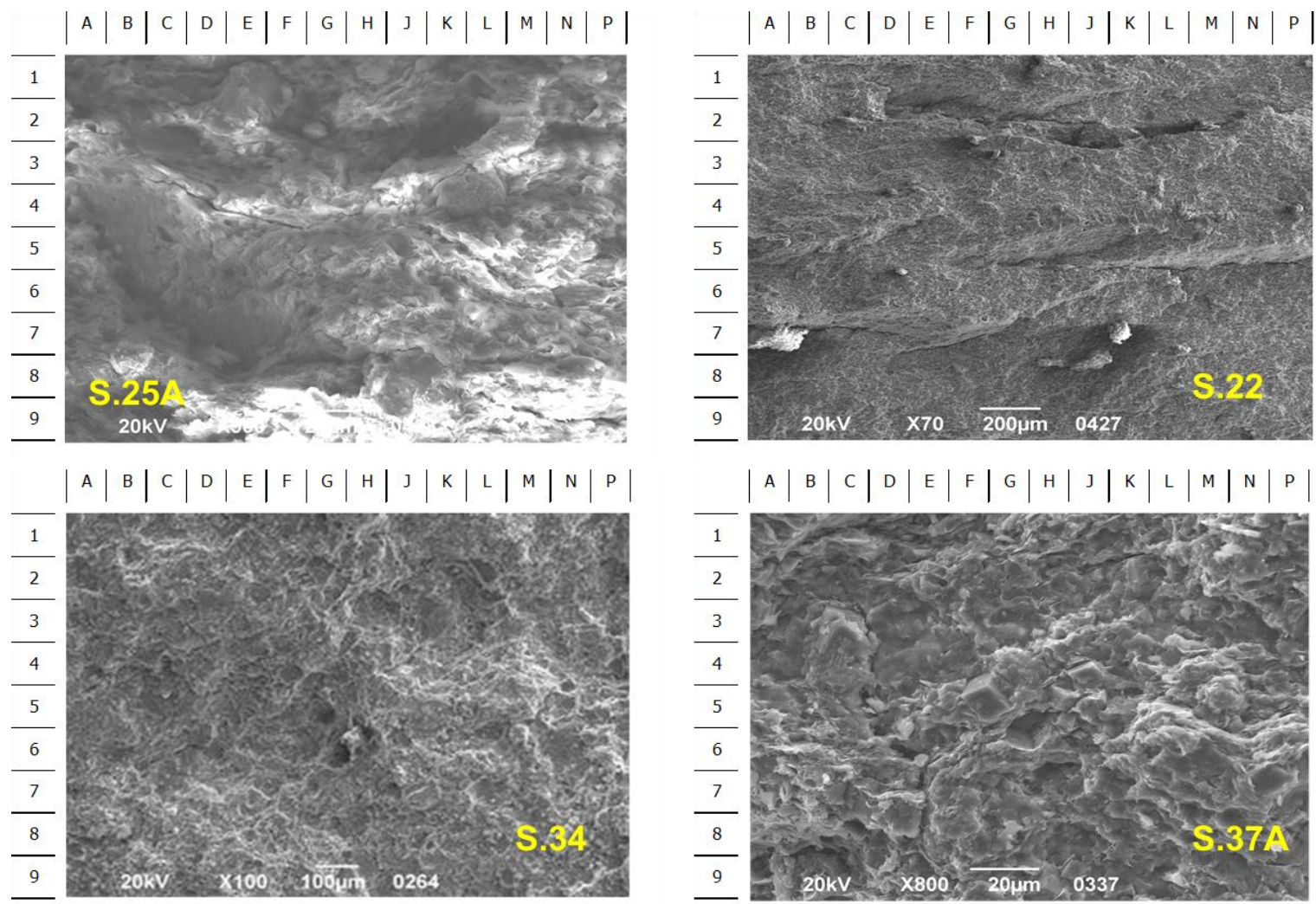

Figure 6. The representative SEM photographs and descriptions at interest zone for both Lower Baong and Belumai Formation.

\section{Rock Descriptions of Figure 6:}

\begin{tabular}{|c|c|c|}
\hline $\begin{array}{l}\text { Sample Code } \\
\text { (depth) }\end{array}$ & $\begin{array}{c}\text { Rock } \\
\text { Classification } \\
\text { Name }\end{array}$ & Descriptions \\
\hline $\begin{array}{c}\text { S. } 22 \\
\text { (depth } 2828 \text { m) }\end{array}$ & Claystone & $\begin{array}{l}\text { Framework grain component comprise of quartz, potash feldspar, metamorphic rock fragment, } \\
\text { micas and carbonaceous material. Skeletal grain composition comprise of slight planktonic forams } \\
\text { and small benthonic forams. No visual macroporosity observed, due to abundant detrital clay } \\
\text { matrix. Only micropore presents between clay minerals with size less than } 10 \mu \mathrm{m} \text {. Microfracture } \\
\text { observed (E-J, 2) and minor organic material are observed. }\end{array}$ \\
\hline $\begin{array}{c}\text { S. 25A } \\
\text { (depth 2944 m) }\end{array}$ & Claystone & $\begin{array}{l}\text { Detrital clay is occur in abundant amount mostly composed by kaolinite, illite and chlorite. } \\
\text { Framework grain component comprise of quartz, sediment rock fragment, and carbonaceous } \\
\text { material. Skeletal grain composition comprise of slight planktonic forams and small benthonic } \\
\text { forams. k-feldspar (C-E, 3-5; EDX Plate E.25B) as labile grain and partial replace to illite and } \\
\text { pyrite (K-L, 4; EDX Plate E.25C). Fracture are observed within clay (C-G, 3-4; K-L, 5; L-P, 8-9). }\end{array}$ \\
\hline $\begin{array}{c}\text { S.34 } \\
\text { (depth } 3263 \text { m) }\end{array}$ & $\begin{array}{c}\text { Sandy } \\
\text { Planktonic } \\
\text { Packestone }\end{array}$ & $\begin{array}{l}\text { Grain supported fabric (calcarenite), low abraded and poor to moderate sorted grains. Skeletal } \\
\text { grain components consist of mainly skeletal grains include planktonic forams, locally associated } \\
\text { with molluscs, brachiopods and small benthonic forams, minor amount of quartz and feldspar. } \\
\text { Carbonaceous material (found as streak, laminar, and fragmental) and micas presence. Carbonate } \\
\text { mud occurs as matrix in minor proportion. No visual macroporosity observed, only micropore } \\
\text { between clay minerals with size less than } 10 \mu \mathrm{m} \text {. Some microfracture observed (A-E, 6-7). }\end{array}$ \\
\hline $\begin{array}{c}\text { S.37A } \\
\text { (depth 3278 m) }\end{array}$ & $\begin{array}{l}\text { Fossilferous } \\
\text { Claystone }\end{array}$ & $\begin{array}{l}\text { Detrital clay is occur in abundant amount mostly composed by kaolinite, illite and chlorite. } \\
\text { Framework grain component comprise of quartz, rock fragment, micas and carbonaceous material. } \\
\text { Skeletal grain composition comprise of slight planktonic forams and small benthonic forams. } \\
\text { Some unstable grains and matrix have been replaced into calcite, dolomite, pyrite, kaolinite and } \\
\text { chlorite. Replacement from labile skeletal grain to calcite (H-J, 6-7; EDX Plate E.37A) and } \\
\text { dolomite (F-G, 4-5; J-K, 4; EDX Plate E.37B) where fracture are also found within clay matrix. }\end{array}$ \\
\hline
\end{tabular}

